\title{
The Curious Case of Acetaldehyde Phenylhydrazone: Resolution of a 120 Year Old Puzzle where Forms with Vastly Different Melting Points Have the Same Structure
}

Carlos Bernades, ${ }^{\dagger}$ Marina Carravetta, ${ }^{\ddagger}$ Simon J. Coles, ${ }^{\ddagger \odot}$ Ernst R. H. van Eck, ${ }^{\S}$ Hugo Meekes, ${ }^{*, \S}{ }^{\S}$ Manuel E. Minas da Piedade, ${ }^{\dagger}$ Mateusz B. Pitak, ${ }^{\ddagger}$ Mike Podmore, ${ }^{\perp}$ Tobian A. H. de Ruiter, ${ }^{\S}$ Leyla-Cann Sögütoğlu, ${ }^{\S}$ René R. E. Steendam, ${ }^{\S ® 0}$ and Terry Threlfall** ${ }^{\ddagger}$

${ }^{\dagger}$ Centro de Química e Bioquímica e Centro de Química Estrutural, Faculdade de Ciências, Universidade de Lisboa, 1749-016 Lisboa, Portugal

${ }^{\ddagger}$ Chemistry, University of Southampton, SO17 1BJ, Southampton, U.K.

${ }^{\S}$ Institute for Molecules and Materials, Radboud University, Heyendaalseweg 135, 6525 AJ Nijmegen, The Netherlands

${ }^{\perp}$ Charles River Laboratories, Harlow, Essex CM19 5TR, U.K.

Supporting Information

ABSTRACT: The solid forms of acetaldehyde phenylhydrazone were investigated in detail over a century ago, with curious results: it was reported that a low melting form could be transformed into a high melting form by trace alkali, and the reverse process could be brought about with trace acid. Our reinvestigation of this puzzle with modern instrumentation has shown that all samples, although exhibiting sharp melting points varying from 56 to $101{ }^{\circ} \mathrm{C}$, have identical IR and solid-state NMR spectra and identical crystal structures. NMR studies of the melts provided the key to the understanding of this strange behavior: differently melting samples did so because they initially melted to liquids with different proportions of the $Z$ and $E$ isomers, although given enough time they all tended to the same equilibrium proportion. The leading role of the isomerization rate in the melt was confirmed in cyclic differential scanning calorimetry experiments and accompanying simulations. In the case of

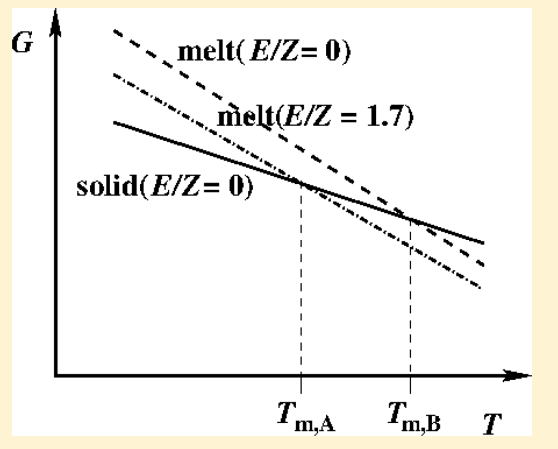
polymorphism, different structures melt to the same liquid. In the present case, the same structure melts to different liquids.

\section{INTRODUCTION}

Emil Fischer first prepared acetaldehyde phenylhydrazone $\left(\mathrm{APH}, \mathrm{C}_{8} \mathrm{H}_{10} \mathrm{~N}_{2}\right.$, Figure 1) in 1877, during an investigation of

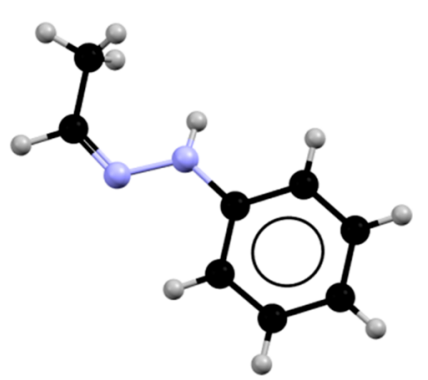

Figure 1. Structure of acetaldehyde phenylhydrazone.

the reactions of phenylhydrazine. ${ }^{1}$ In 1896 he reported that there were three forms of it, with melting points of $63-65{ }^{\circ} \mathrm{C}$, $80{ }^{\circ} \mathrm{C}$, and $98-101{ }^{\circ} \mathrm{C}$. At that time the concepts of multiple solid-state forms were still in their infancy, so this observation attracted much attention. The compound was subsequently reinvestigated by several groups including Causse, ${ }^{3}$ Bamberger and Pemsel, ${ }^{4}$ Lockemann and Liesche, ${ }^{5}$ Robertson, ${ }^{6}$ and Laws and Sidgwick. ${ }^{7}$ Lockemann and Liesche came to the conclusion that there were only two distinct forms, of melting point 56 and $98{ }^{\circ} \mathrm{C}$. Causse identified several novel reaction products, one with a melting point of $80{ }^{\circ} \mathrm{C}$, a source of some confusion, because the form with a melting point of $80{ }^{\circ} \mathrm{C}$ reported by Fischer was undoubtedly the intended compound. Laws and Sidgwick thought that samples of melting point 80 ${ }^{\circ} \mathrm{C}$ were merely solid solutions of the low and high melting forms.

According to all of these authors, crystallization of aqueous ethanolic solutions containing trace alkali $\left(\mathrm{NaOH}, \mathrm{Na}_{2} \mathrm{CO}_{3}\right.$, $\mathrm{KOH}, \mathrm{Ba}(\mathrm{OH})_{2}$, ammonia) will yield the high melting form. A solution treated with trace acid $\left(\mathrm{HCl}, \mathrm{HNO}_{3}, \mathrm{H}_{2} \mathrm{SO}_{4}\right)$ will yield the low melting form.

The low melting solid can be converted to the high melting form by slurrying in faintly alkaline solution, or by allowing ammonia vapor to permeate the solid for a few minutes. Conversely, the high melting solid can be converted to the low melting solid by slurrying in a faintly acid solution or by

Received: September 27, 2018

Revised: December 21, 2018

Published: January 7, 2019 
treatment with acidic vapors $\left(\mathrm{HCl}, \mathrm{SO}_{2} \cdot \mathrm{H}_{2} \mathrm{O}\right)$. The quantities of acid and alkali described are very small; we have found that as little as 1000th of a molar equivalent will drive these changes. Lockemann and Liesche report that allowing acetaldehyde phenylhydrazone to stand in a desiccator over concentrated sulfuric acid, or keeping it in an atmosphere of hydrogen that had been previously dried over sulfuric acid, will catalyze the formation of the low temperature form. So, minute concentrations of acids will bring about change. Even weak acids will work: carbon dioxide in the atmosphere was reported to be effective on wet samples. Clearly these results are thermodynamically impossible for a polymorphic system. Indeed, catalysis can accelerate a spontaneous polymorphic transformation (one accompanied by a negative Gibbs energy change) that is too slow to be observed in a reasonable time period, by lowering its activation energy. But it is impossible to catalytically promote a nonspontaneous process, without any additional energy input. Thus, if the high temperature form is also the thermodynamically stable form at room temperature, then it is impossible to spontaneously transform it to the low melting form using only catalysis. Alternatively, if there is a solid-solid phase transition relating the low and high melting forms at a temperature $\left(T_{\text {trs }}\right)$ between room conditions $\left(T_{\text {room }}\right)$ and the melting point $\left(T_{\text {fus }}\right)$, then the low melting form will be the stable one at $T_{\text {room }}$ and it will be impossible to transform it to the high melting form, unless the temperature is increased above $T_{\text {trs }}$. Nevertheless, the final product from a catalyzed reaction, in the strict sense of the term, cannot be dependent on the nature of the catalyst. Furthermore, in the case of APH the changes are repeatable, so that a sample can be cycled between the two forms. ${ }^{5}$ The melting points described by the various authors and for the same authors by different procedures varied significantly, but all authors agreed on the presence of at least a low melting and a high melting form.

Several of these authors describe the vacuum distillation of the product. Indeed, Fischer thought it necessary to do so to purify it, but the later authors, presumably having access to better quality starting materials, were able to crystallize the different APH forms without a purification step. The conclusions as to the product of distillation show some discrepancy: Fischer described the process as giving the low melting form, while both Bamberger and Pemsel ${ }^{4}$ and Laws and Sidgwick ${ }^{7}$ reported obtaining the same form as the starting material from the distillation. If this were the case it would imply that the difference between the forms must have an intramolecular origin, for example, desmotrophy or configurational isomerism, rather than depending on variation of crystal packing. Fischer ${ }^{2}$ also noted that the conversion or partial conversion of one form to the other on storage was not entirely controllable. Given the extreme sensitivity to acid later noted by Lockermann and Liesche, this is hardly surprising.

The results of Laws and Sidgwick also suggest that the two forms are not interconverted on dissolution or fusion. They were able to construct convincing composition-melting curves from crystals from the melt or from solution. In this way they were able to calculate that the APH crystals of melting point around $80{ }^{\circ} \mathrm{C}$, from neutral liquids, that is, water or nonpolar solvents, consisted of $75 \%$ high melting and $25 \%$ low melting form.

We were intrigued by the possible structural differences and reasons for the sensitivity to trace acid or base exposure, and believed that a reinvestigation with modern instrumental techniques would be rewarding. In particular at the start of this study it was thought that this compound might show intramolecular differences between the two forms. Examples of this are uncommon ${ }^{8,9}$ but are of interest in connection with possible second-order solid-state transitions. We also considered that unusual thermodynamic relationships might be involved and undertook both differential scanning calorimetry (DSC) and solution calorimetric studies. In the end, NMR experiments on melting crystals led us to a hypothesis for explaining the different melting points, which was confirmed by cyclic DSC experiments and simulations of the latter.

\section{EXPERIMENTAL METHODS}

The study was conducted at different sites, in Southampton, Lisbon, and Nijmegen, and was performed on samples prepared in Southampton, referred to as S-crystals or S-samples, as well as on samples prepared in Nijmegen, referred to as $\mathrm{N}$-crystals or $\mathrm{N}$-samples.

Sample Preparation. S-Samples. A total of $3.0 \mathrm{~g}$ of acetaldehyde was dissolved in cold (ice-bath) aqueous ethanol prepared from 2.0 $\mathrm{mL}$ of water and $12.0 \mathrm{~mL}$ of ethanol with stirring. A total of $6.0 \mathrm{~g}$ of fresh phenylhydrazine was added dropwise. The solution was divided into two, and trace alkali (e.g., a few drops of concentrated ammonia, but more makes no difference) was added to one portion in order to prepare the high melting form. Trace acid (e.g., a few drops of conc. $\mathrm{HCl}$ ) was added to the other portion to prepare the low-melting form. After being stirred in the cold for one to $2 \mathrm{~h}$, APH crystals began to appear, and were harvested. The color was pale cream, provided that good quality reagents were used and the solutions were kept cold throughout. The lower melting form sometimes crystallized with difficulty. Seeding with crystals prepared by treating the high-melting solid with acid was always effective in producing immediate crystallization. The typical crystal habit was nacreous flakes, although there were sometimes chunkier plates. When solutions were kept overnight in the refrigerator, the crystals generally increased in size. After several days, even in the cold, samples began to discolor, especially the acid treated ones, whether kept dry or as a slurry.

The earlier literature describes conversion times of hours, but at least on the scale used here, 10 min was generally sufficient to bring about conversion, unless weak or extremely dilute acids and alkalies were used.

$\mathrm{N}$-Samples. For $\mathrm{N}$-samples an alternative procedure was used, including an intermediate crystallization to avoid an influence of the synthesis solution on the effect of adding acid or base. A total of 10.4 $\mathrm{mL}$ of acetaldehyde (5-10\% excess) was added to a cooled solution of aqueous ethanol prepared from $6.7 \mathrm{~mL}$ of water and $40.0 \mathrm{~mL}$ of ethanol. A total of $18.2 \mathrm{~mL}$ of phenylhydrazine was added dropwise to the mixture in the cold while stirring. After the addition the mixture was left stirring for $15 \mathrm{~min}$ and then set aside for crystals to appear (scratching, extra cooling, or addition of water was used to speed up crystallization). After collecting, the crystals were washed with some aqueous ethanol and dried. The high and low melting forms were obtained using fast recrystallization by slightly heating and dissolving the product in alcoholic solution, in the presence of a trace (1:100) of $\mathrm{NaOH}$ or $\mathrm{HCl}$, respectively, and subsequent cooling.

Single Crystal X-ray Diffraction Studies. Single-crystal X-ray diffraction analyses of S-samples of high melting point $\left(92{ }^{\circ} \mathrm{C}\right)$, low melting point $\left(51{ }^{\circ} \mathrm{C}\right)$, and Causse's condensation product $\left(\mathrm{C}_{18} \mathrm{H}_{22} \mathrm{~N}_{4}, \mathrm{mp} 74{ }^{\circ} \mathrm{C}\right)$ were performed in Southampton using a Bruker APEXII CCD diffractometer mounted at the window of a Bruker FR591 rotating anode (Mo K $\alpha$ radiation, $\lambda=0.71073 \AA$ ) and equipped with an Oxford Cryosystems cryostream device. Data were processed using the Collect package, ${ }^{10}$ and unit cell parameters were refined against all data. An empirical absorption correction was carried out using SADABS. ${ }^{11}$ All structures were solved by direct methods using SHELXS- $97^{12}$ and refined on $F_{0}^{2}$ by full-matrix least-squares refinements using SHELXL-2014. ${ }^{13}$ All non-hydrogen atoms were refined with anisotropic displacement parameters. All hydrogen atoms (except Hla in the two acetaldehyde phenylhydrazone samples) were added at calculated positions and refined using a riding model with 
isotropic displacement parameters based on the equivalent isotropic displacement parameter $\left(U_{\mathrm{eq}}\right)$ of the parent atom.

X-ray Powder Diffraction. Powder diffraction data were collected in Southampton on S-samples using a Bruker D8 Advance diffractometer operating in Bragg-Brentano $\theta / 2 \theta$ geometry. $\mathrm{Cu} \mathrm{K} \alpha 1$ $(\lambda=1.5406 \AA)$ radiation was generated from a sealed tube operating at $40 \mathrm{kV}, 40 \mathrm{~mA}$, and monochromated using a Ge single crystal. Intensities were recorded on a standard scintillation counter with a step size of $0.02^{\circ}$ and an acquisition time of $1 \mathrm{~s}$ per step.

Infrared Spectra. Infrared spectra on the neat S-solids were obtained from a Nicolet Omnic spectrometer by the diamond anvil method over the range 3700 to $370 \mathrm{~cm}^{-1}$. Diffuse reflectance infrared Fourier-transform (DRIFT) spectra of S-samples studied in Lisbon were recorded in the range $4000-500 \mathrm{~cm}^{-1}$ using a Nicolet 6700 spectrometer. The resolution was $4 \mathrm{~cm}^{-1}$ and the samples were $\sim 5 \%$ (w/w) APH in KBr.

NMR Spectra. ${ }^{13} \mathrm{C}$ NMR solid-state spectra of S-samples were obtained in Southampton on a Varian infinity Plus 400 spectrometer using a $\mathrm{T} 34 \mathrm{~mm}$ probe spun in a $4 \mathrm{~mm} \mathrm{ZrO}_{2}$ rotor and the melt spectra at $98{ }^{\circ} \mathrm{C}$ on both the Varian Infinity and a $300 \mathrm{MHz}$ Bruker spectrometer.

In Nijmegen ${ }^{13} \mathrm{C}$ single pulse and CPMAS spectra were recorded on $\mathrm{N}$-samples both on an $850 \mathrm{MHz}$ and a $400 \mathrm{MHz}$ Agilent solid state NMR spectrometer at various temperatures. On the $850 \mathrm{MHz}$ system, a $3.2 \mathrm{~mm} \mathrm{T3}$ model probe was used, resonant at $213 . \mathrm{xHz}$ for ${ }^{13} \mathrm{C}$ and $849.7 \mathrm{MHz}$ for ${ }^{1} \mathrm{H}$. A $3.2 \mathrm{~mm}$ APEX design probe was used on the $400 \mathrm{MHz}$ system, resonating at $100.5 \mathrm{x} \mathrm{MHz}$ for ${ }^{13} \mathrm{C}$ and 399.995 $\mathrm{MHz}$ for ${ }^{1} \mathrm{H}$. Typically rf-field strengths of $90 \mathrm{kHz}$ and $50 \mathrm{kHz}$ for proton decoupling were employed, while for cross-polarization a 60 $\mathrm{kHz}$ rf-field on both ${ }^{13} \mathrm{C}$ and ${ }^{1} \mathrm{H}$ was used. Magic angle spinning speeds varied between 5 and $18.5 \mathrm{kHz}$. NMR spectra were acquired for the melt, for the solid phase and for partially solidified samples. By employing CPMAS, the ${ }^{13} \mathrm{C}$ NMR spectra of the solid phase were detected selectively, while ${ }^{13} \mathrm{C}$ spectra without decoupling show only narrow lines for the mobile fraction (i.e., liquid phase and the methyl groups). Solid and melt phase ${ }^{1} \mathrm{H}$ NMR signals are also easily distinguished as the solid phase signals are much broader than those for the melt.

Differential Scanning Calorimetry. The DSC traces were recorded in Southampton with a Mettler Toledo DSC $821^{\mathrm{e}}$ instrument using a scan rate of $10{ }^{\circ} \mathrm{C} \cdot \mathrm{min}^{-1}$. The samples with a mass of $4.0-7.5 \mathrm{mg}$ were analyzed in sealed $\mathrm{Al}$ crucibles. The instrument was calibrated with indium $\left(99.999 \%, \mathrm{mp} 156.6{ }^{\circ} \mathrm{C}, \Delta_{\text {fus }}{ }^{\circ}\right.$ $\left.=28.45 \mathrm{~J} \cdot \mathrm{g}^{-1}\right)$.

DSC experiments on S-samples studied in Lisbon were performed at a scan rate of $5{ }^{\circ} \mathrm{C} \cdot \mathrm{min}^{-1}$ on a PerkinElmer DSC 7 instrument, using 1-6 mg of substance contained in sealed $\mathrm{Al}$ crucibles. The temperature scale of the apparatus was calibrated at the same heating rate by taking the onsets of the fusion peaks of benzoic acid (NIST SRM 39j, 99.9996\%, mp $122.37^{\circ} \mathrm{C}$ ), indium (PerkinElmer, $99.999 \%$, $\mathrm{mp} 156.63{ }^{\circ} \mathrm{C}$ ), lead (Goodfellow, $99.995 \%$, mp $327.46{ }^{\circ} \mathrm{C}$ ), and zinc (PerkinElmer, $99.999 \%, \mathrm{mp} 419.50{ }^{\circ} \mathrm{C}$ ). The heat flow scale was calibrated based on the enthalpy of fusion of the indium standard $\left(\Delta_{\text {fus }} h^{\circ}=28.45 \mathrm{~J} \cdot \mathrm{g}^{-1}\right)$.

The DSC traces recorded in Nijmegen were measured using a Mettler Toledo DSC $822^{\mathrm{e}}$ instrument with a FRS5 sensor and a Julabo FT900 immersion cooler. The scan rate was $5{ }^{\circ} \mathrm{C} \cdot \mathrm{min}^{-1}$. All samples had masses in the range 5-8 $\mathrm{mg}$ and were measured in sealed $40 \mu \mathrm{L} \mathrm{Al}$ crucibles. The instrument was calibrated with indium (99.999\%, mp $\left.156.6{ }^{\circ} \mathrm{C}, \Delta_{\text {fus }} h^{\circ}=28.45 \mathrm{~J} \cdot \mathrm{g}^{-1}\right)$.

Solution Calorimetry. Enthalpies of solution in ethanol (Panreac, 99.9\%) were determined in Lisbon on S-samples with an electrically calibrated isoperibol Thermometric Precision Solution calorimeter (model 2225) adapted to a Thermal Activity Monitor thermostatic water jacket (TAM 2227). The jacket temperature was maintained at $25.3^{\circ} \mathrm{C}$. The general procedure has been previously described, ${ }^{14}$ and further details are given in the Supporting Information.

Hot-Stage Microscopy. A Leitz $2500 \mathrm{M}$ microscope in conjunction with a Mettler-Toledo FP82HT hot stage and FP90 processor was used in Southampton for comparison of the melting processes observed by DSC.

Melting Points on the Kofler Block. The Kofler type WME hotblock from Wagner and Munz (Munich) was used in Southampton for the initial rapid determination of the melting points. Azobenzene and benzoic acid were used to check the calibration.

Purity. At the request of a reviewer, we have re-examined the DSC, NMR, and PXRD charts for evidence of impurity. The results are discussed in Supporting Information.

Computational Chemistry. The quantum chemical calculations were performed in Lisbon with Gaussian $09^{15}$ using the MP2 $2^{16-19}$ and B3LYP-D3 ${ }^{20-23}$ models, and the aug-cc-pVDZ basis set. ${ }^{24-27}$ All electronic energies were calculated over optimized geometries at the corresponding level of theory (i.e., MP2/aug-cc-pVDZ and B3LYP$\mathrm{D} 3$ /aug-cc-pVDZ), followed by a frequencies calculation. No imaginary frequencies were obtained, indicating that the optimized structures corresponded to local minima. The thermal corrections were obtained using unscaled frequencies, since the purpose of the calculations was to determine the enthalpic, entropic, and Gibbs energy differences between the two APH isomers in the gaseous phase, and the effect of a scaling factor cancels when such differences are computed.

\section{RESULTS AND DISCUSSION}

Confirmation of Earlier Results from the Literature. We repeated the experiments described in the earlier literature on S-samples and confirmed that they all proceeded as described. The only discrepancy, which has already been discussed and can be ascertained by comparing the various accounts in refs $2-7$, is that the melting points are not entirely reproducible. On the whole the low melting samples melted around $60{ }^{\circ} \mathrm{C}$, but the highest reported melting point for the high-melting material was often a little more difficult to achieve and the obtained value often varied between 90 and $95{ }^{\circ} \mathrm{C}$ depending on the preparation. Interconversion by contact with alkali or acid, as mentioned in the introduction, seemed harder for some samples than others, but that may have been due to the underlying $\mathrm{pH}$ of the original solutions, or to the state of aggregation of the crystals. APH of approximately $80{ }^{\circ} \mathrm{C}$ melting point was also readily obtainable, for example, from neutral solutions, ${ }^{7}$ so it is unsurprising that this was thought to be a third form. The only experiment considered unnecessary to repeat was the distillation described by several of the authors, since it was apparent with hindsight that the result must be sensitive to the acidity of the environment.

Confirmation of Earlier Results from Literature Using State-of-the-Art Techniques. Thermal Analysis. All the thermal measurements at all three sites confirmed that acid treated samples melted at substantially lower temperatures than untreated samples or those subjected to contact with alkalis. Representative DSC traces for S-samples of low and high melting points are illustrated in Figure 2. The peak shapes and peak widths are not vastly dissimilar, thereby excluding explanations of difference based on lowering of melting point by impurity. Hot stage microscopy paints the same picture. Melting points determined on the Kofler block also displayed similar differences, with one additional strange feature. When the high melting form was presented as a thin trickle of isolated crystals on the slide, then as soon as the melting point was reached, the melting process "ran back" along the slide down to about $80^{\circ} \mathrm{C}$, even though the crystals were not in contact. It is not known whether this was due to the release of acid vapors during melting which then lowered the melting point of the remaining crystals. The phenomenon was seen repeatedly, but melting never seemed to reach below $80{ }^{\circ} \mathrm{C}$. It is possible 


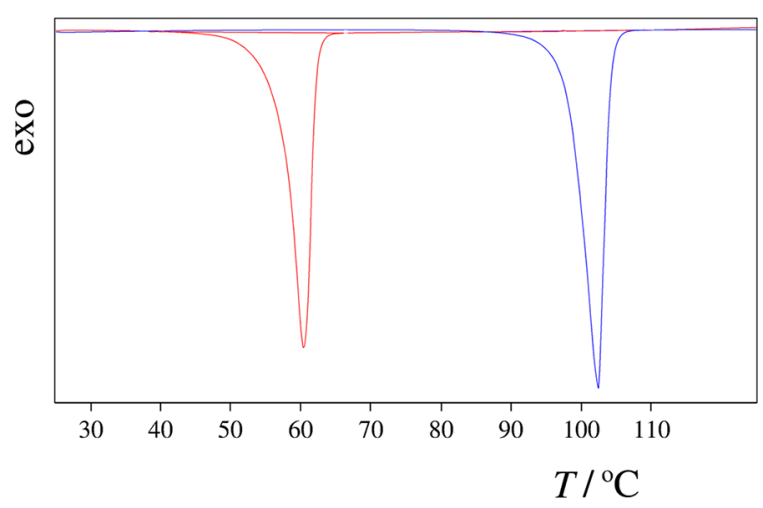

Figure 2. DSC traces showing the endothermic melting peaks of high melting (blue; $-184.14 \mathrm{~J} \cdot \mathrm{g}^{-1}$, onset $97.8^{\circ} \mathrm{C}$ ) and low melting (red; $-164.14 \mathrm{~J} \cdot \mathrm{g}^{-1}$, onset $56.7^{\circ} \mathrm{C}$ ) forms of S-samples of APH.

therefore that a condensation product was being formed by the decomposition of the APH crystals. More on the condensation product can be found in the Supporting Information.

The results of a comparison study by DSC and by solution calorimetry of seven S-samples (Figure 3) showed no correlation whatsoever between molar enthalpies of solution, temperatures of fusion, or enthalpies of fusion. Since all samples have the same crystal structure with the APH molecule in the $Z$ conformation (see below), the fact that the enthalpies of solution and fusion span $2.3 \mathrm{~kJ} \cdot \mathrm{mol}^{-1}$ and 7.6 $\mathrm{kJ} \cdot \mathrm{mol}^{-1}$ ranges, respectively, cannot be attributed to lattice energy differences. It is also very unlikely that they reflect particle size changes, since lattice enthalpy-size dependencies of this magnitudes are only expected at the nanometer scale, which is not the case for the materials used in the present work. $^{28}$ The observed $\Delta_{\text {sol }} H_{\mathrm{m}}^{\circ}$ differences are, therefore, most likely related to differences in trace acid/base content of the samples which, upon dissolution, can contribute to the calorimetric measurements in two ways: (i) their own enthalpy of solution; (ii) promotion of different $Z \rightarrow E$ conversion extents on the way to equilibrium, ${ }^{29-33}$ within the time scale of the calorimetric experiments. The influence of these traces in $\Delta_{\text {fus }} H_{\mathrm{m}}^{\circ}$ is discussed below.

IR Spectral Characterization. Spectral measurements whether conducted in Lisbon or Southampton, confirmed the identity of all solid S-samples irrespective of melting point (except for the sample of Causse's condensation product initially examined by IR and ${ }^{13} \mathrm{C}$ solid-state NMR spectroscopy at Southampton (see Supporting Information), which caused considerable confusion.) In Figure 4 diffuse reflectance infrared Fourier-transform (DRIFT) spectra of three APH Ssamples with considerably different DSC fusion temperature onsets show no difference.

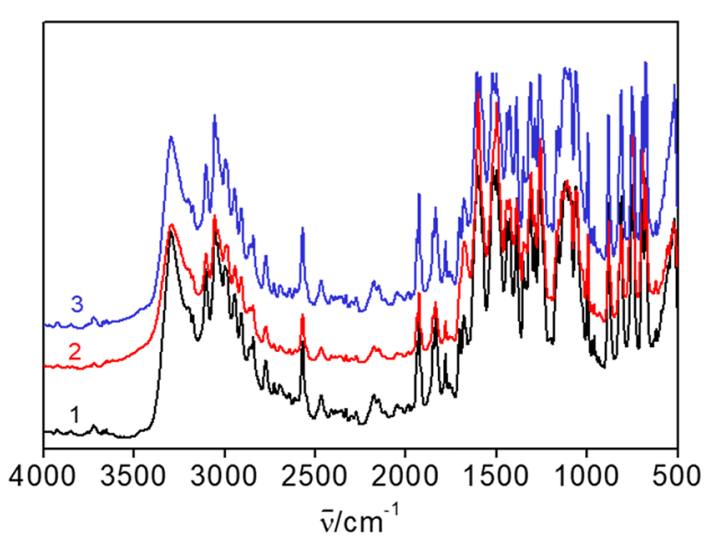

Figure 4. Diffuse reflectance infrared Fourier-transform spectra recorded in Lisbon of three APH S-samples with considerably different DSC fusion temperature onsets: (1) $T_{\text {on }}=60.4 \pm 0.6{ }^{\circ} \mathrm{C}$; (2) $T_{\text {on }}=65.9 \pm 2.3{ }^{\circ} \mathrm{C}$; (3) $T_{\text {on }}=93.4 \pm 3.5{ }^{\circ} \mathrm{C}$.

X-ray Diffraction and Crystal Structure. The PXRD traces of low and high melting S-samples were also very similar, except for a small impurity peak at $12.3^{\circ} 2 \theta$ (Figure 5). The DSC charts (Figure 2) already showed that there is no transformation between room temperature and the melting point. In view of these results, it is unsurprising that the PXRD traces, Figure 5, are similar.

This identity was further confirmed by the superimposibility of the structures determined by single crystal X-ray diffraction. The unit cells of S-crystals of APH of any melting point were always identical, as shown in the CIF files of two typical samples of melting point 51 and $92{ }^{\circ} \mathrm{C}$. The molecular structures of those crystals of vastly different melting point are shown overlaid in Figure 6. The differences in unit cell dimensions are less than often found in repeat measurements of crystals of identical structure. ${ }^{34}$

In the crystal structure each molecule is hydrogen bonded via weak (3.166(4) Å) intermolecular $\mathrm{N}-\mathrm{H} \cdots \mathrm{N}$ hydrogen bonds propagating in chain-like fashion along the crystallographic $b$-axis. As the preliminary single crystal analysis of high melting and low melting forms initially returned identical unit cells, we had originally supposed that this might be one of the
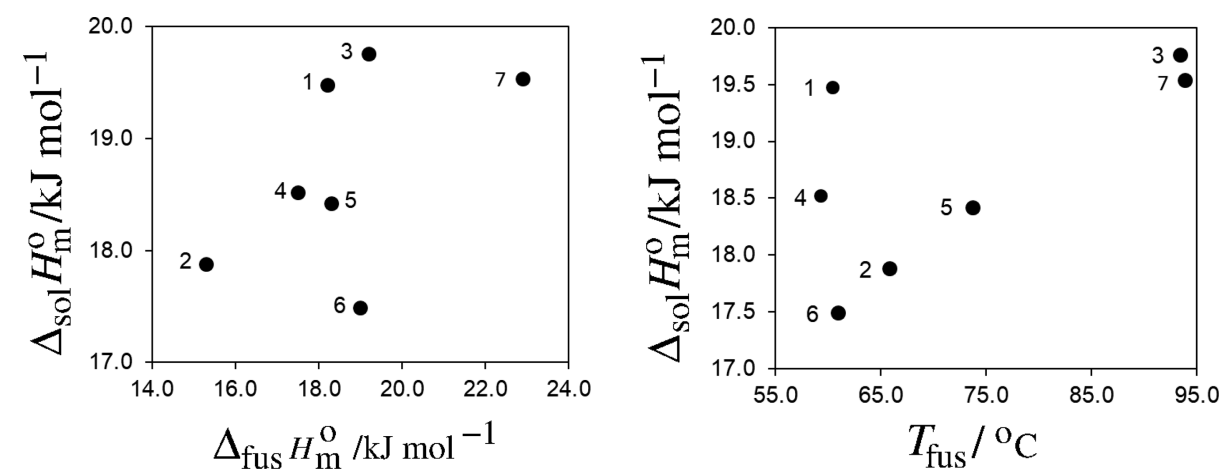

Figure 3. Plots showing the lack of correlation between the standard molar enthalpies of solution of different S-samples of APH in ethanol, at 25 ${ }^{\circ} \mathrm{C}$, and the corresponding enthalpies of fusion (left) or temperatures of fusion (right). 


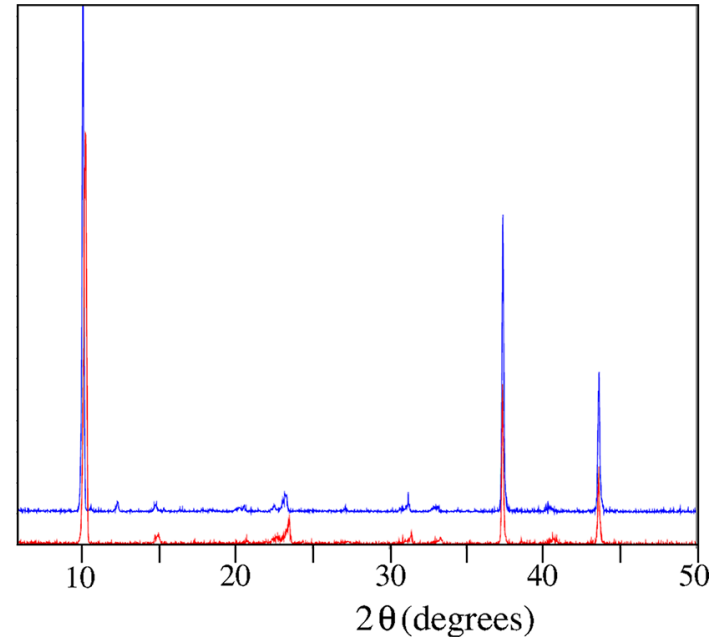

Figure 5. Experimental PXRD diffractograms of high melting (blue) and low melting (red) S-samples of APH.

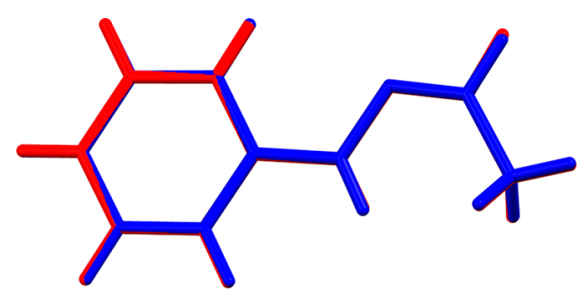

Figure 6. Molecular structure overlap of high melting (blue) and low melting (red) forms of S-crystals of APH.

rare incidences when polymorphs or similar compounds showed closely similar unit cells. However, when the full data were collected, identical crystal structures were obtained for both forms at $120 \mathrm{~K}$ (Figures 6 and 7). To check that this was not an instance of phase transformation below room temperature, the experiments were repeated at room temperature with the same outcome.

The asymmetric part of the monoclinic $C c$ unit cell in both crystal structures contains one fully ordered molecule of APH in the $Z$ conformation. Quantum chemistry calculations at the MP2/aug-cc-pVDZ and B3LYP-D3/aug-cc-pVDZ indicated that for the isolated molecule in the gas phase the $E$ conformation is slightly more stable than the $Z, \Delta_{\mathrm{r}} G_{\mathrm{m}}^{\circ}(E \rightarrow$ $Z)>0$ (see Supporting Information), the predicted molar fraction ratios under equilibrium being $x_{E} / x_{Z}=1.01(\mathrm{MP} 2 /$ aug-cc-pVDZ) and $x_{E} / x_{Z}=1.09$ (B3LYP-D3/aug-cc-pVDZ), respectively. This preference is in accord with the experimental results for melt and solution (see below). The preference for the $Z$ conformer in the crystalline state should, therefore, be due to packing effects.
Solid State NMR. It was then supposed that one of the forms must have transformed under the influence of the $\mathrm{X}$ radiation, and it was decided to run solid-state NMR (ssNMR) spectra on freshly prepared S-specimens to check this. As can be seen in Figure 8, the spectra of both forms are identical apart from small intensity differences within the expected limits due to the relaxation time dependence on the collection time.
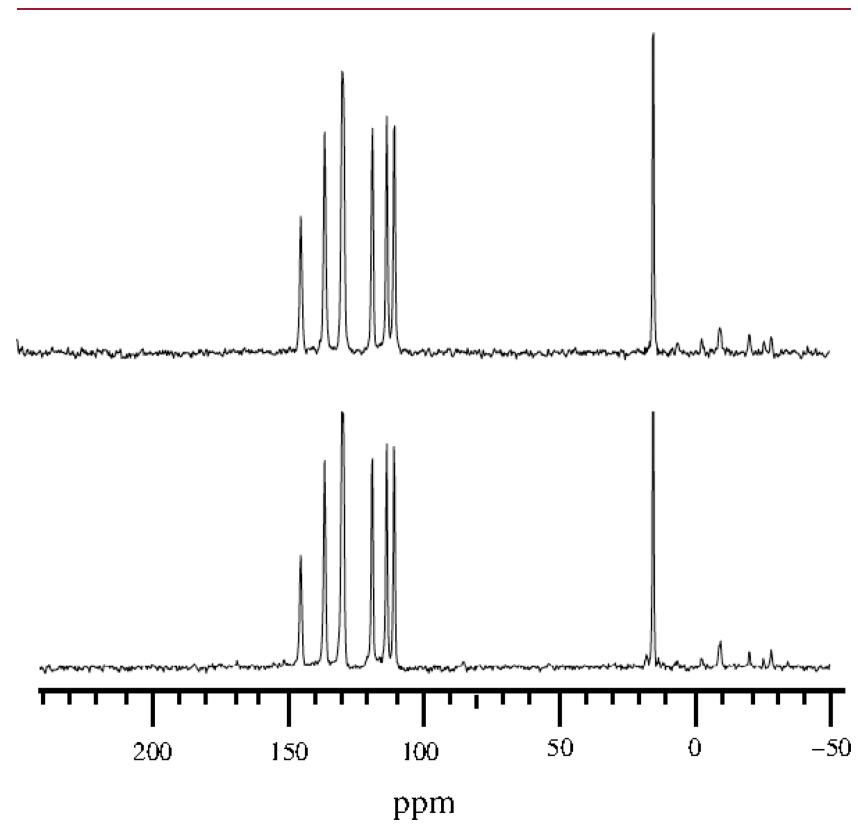

Figure $8 .{ }^{13} \mathrm{C}$ ssNMR spectra of low melting (top) and high melting (bottom) S-samples of APH.

To check that the pressure exerted by the anvil or the pressure due to sample spinning had not brought about transformation, the melting point was checked before and after the spectral examination. There was no change. When samples were remade for a repeat ssNMR examination, the crystal structures were run again, with the same results as previously. We took the opportunity to check the thermal behavior before and after single crystal examination, and before and after the PXRD examination by hot stage microscopy. There was no change.

The results described above diverted our attention to the molten phase of APH, which we studied with ssNMR for melting N-crystals.

Assignment of the individual carbon nuclei (Figure 9) was accomplished by comparing a ${ }^{13} \mathrm{C}$-single pulse-spectrum of an $\mathrm{APH}$ melt with and without decoupling shown in Figure 10. For that we used the melt of a low-melting $\mathrm{N}$-sample. For the assignment of $\mathrm{C} 5,7$ and $\mathrm{C} 4,8$ information on ${ }^{1} \mathrm{H}$ NMR was
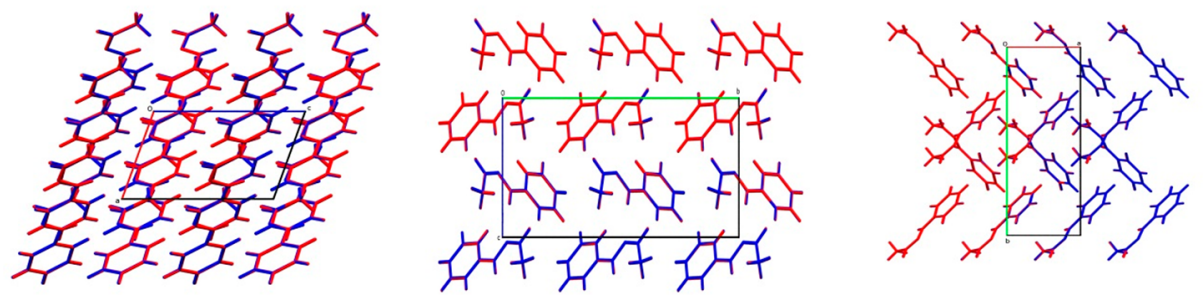

Figure 7. Crystal structure overlap of high melting (blue) and low melting (red) forms of S-crystals of APH; left: Crystal packing viewed down crystallographic $a$-axis; middle: Crystal packing viewed along the crystallographic $b$-axis; right: Crystal packing viewed down crystallographic $c$-axis. 
<smiles>C/C=N\Nc1ccccc1</smiles>

Figure 9. APH numbering of ${ }^{13} \mathrm{C}$ spectra (only the $Z$-isomer is shown). The same numbering is used for ${ }^{1} \mathrm{H}$ spectra, but with number 3 assigned to the $\mathrm{N}-\mathrm{H}$ proton instead.
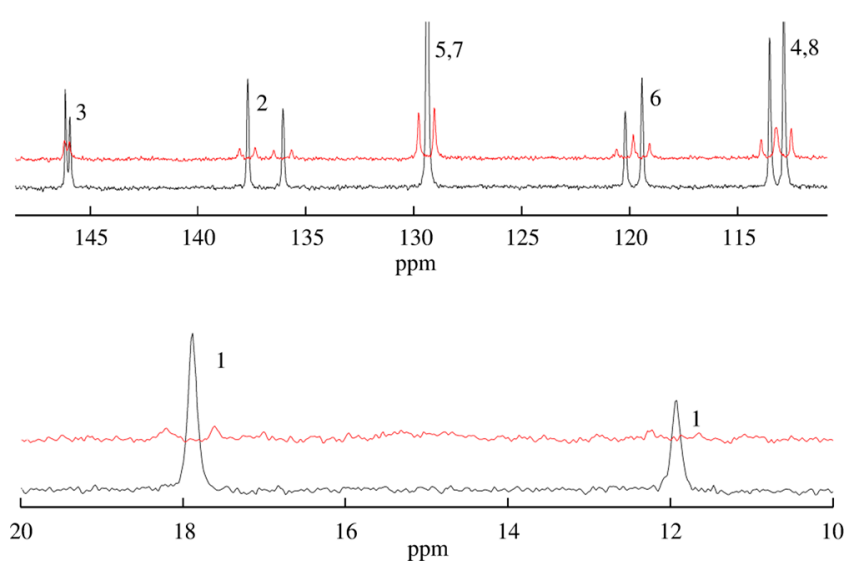

Figure 10. ${ }^{13} \mathrm{C}$ single pulse-spectrum $(850 \mathrm{MHz}$, MAS-rate $18.5 \mathrm{kHz})$ of the melt of a low-melting $\mathrm{N}$-sample, with decoupling (lower traces in black, $50 \mathrm{kHz}, n=88$ ) and without decoupling (upper traces in red, $n=80)$.

used. This assignment is in agreement with other ${ }^{13} \mathrm{C}$ data of phenylhydrazones found in the literature. ${ }^{35,36}$

Unlike in the solid state spectra, in the melt two forms are clearly visible. The difference in chemical shift is largest for the methyl group ( $\mathrm{C} 1)$, whereas the meta carbons $(\mathrm{C} 5, \mathrm{C} 7)$ seem to be practically equivalent for both species. To find the origin of these two forms, we performed temperature dependent NMR measurements of the melting process for a low-melting $\mathrm{N}$-sample.

Figure 11 shows a ${ }^{13} \mathrm{C}$-single pulse spectrum of such a melting $\mathrm{N}$-sample. The middle peak of the spectrum can be assigned to $Z$ (solid) because it has vanished at $59{ }^{\circ} \mathrm{C}$ when the solid is fully melted. Two other peaks that grow in intensity with temperature are visible, left and right of the $Z$ (solid)

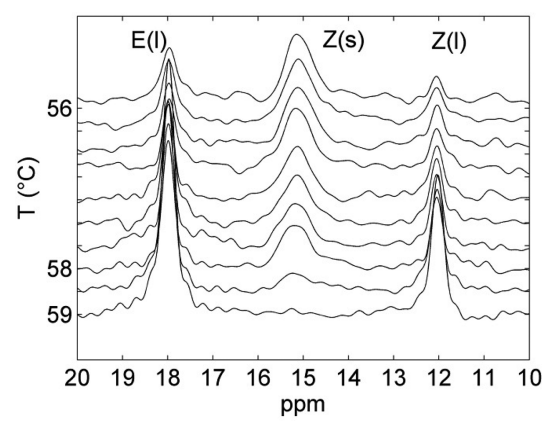

Figure 11. Temperature dependent ${ }^{13} \mathrm{C}$-spectrum of a low melting $\mathrm{N}$ sample; close-up on the methyl peaks (C1) $(100 \mathrm{MHz}, 50 \mathrm{kHz}$ decoupling, MAS-rate: $5 \mathrm{kHz}, 10 \mathrm{~min} /$ spectrum). The vanishing middle peak can be assigned to $Z(s)$, both $E(1)$ and $Z(1)$ peaks grow in intensity. peak. The ratio of these peaks is reasonably constant as can be seen in Figure 12. Interestingly, a similar measurement for a

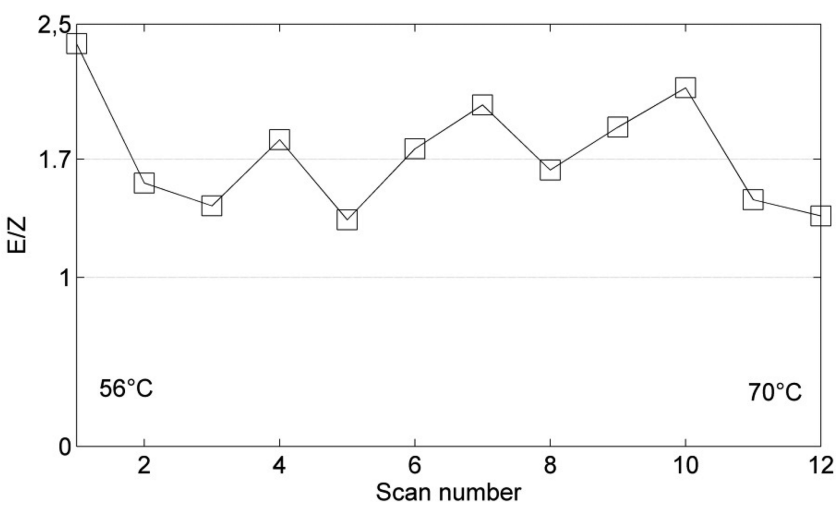

Figure 12. Ratio between area of $E(1)$ and $Z(1)$ peaks as measured during melting of a low melting $\mathrm{N}$-sample (Figure 11). The average value of $E(1) / Z(1)$ is approximately 1.7 . The first scan was taken at 56 ${ }^{\circ} \mathrm{C}$ and scan 12 at $70{ }^{\circ} \mathrm{C}$.

high-melting $\mathrm{N}$-sample shows the same two peaks, but with a ratio that increases from 0.2 at $95{ }^{\circ} \mathrm{C}$ to 1.7 at $105{ }^{\circ} \mathrm{C}$ (Figure 13). The latter value of 1.7 is equal to the average value found in Figure 12.

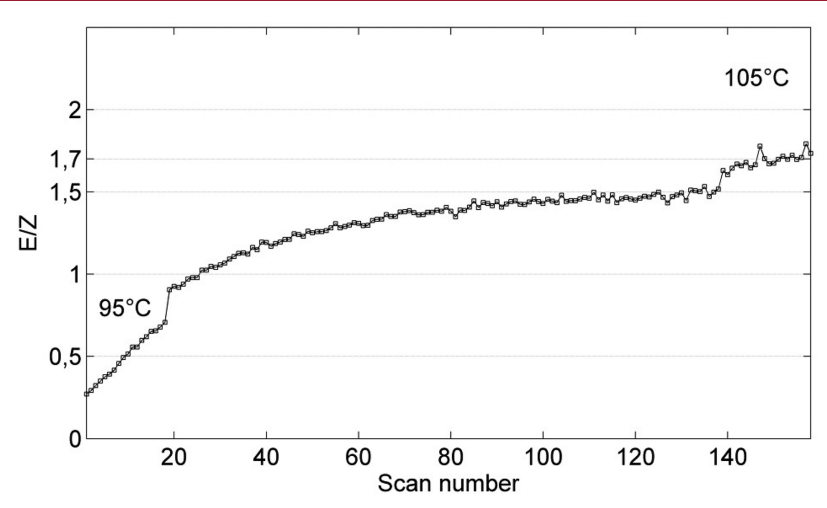

Figure 13. Ratio between area of $1(\mathrm{eft})$ and $(\mathrm{r})$ ight peaks as measured from a ${ }^{1} \mathrm{H}$ NMR spectrum obtained during melting of a high melting $\mathrm{N}$-sample. (Originally ${ }^{1} \mathrm{H}-\mathrm{NMR}$ spectra were recorded for both low and high melting samples, but this proved to be less informative for the melting of a low melting sample due to broadened peaks for the solid. When the isomerization is slow, as in the high-melting sample, this is less of an issue because the larger part of the isomerization happens when the solid has already melted. A rerun of ${ }^{13} \mathrm{C}$ spectra for the high melting sample was not performed as it would only give more detail about the composition of the initial melt, but would not change the general picture of an increasing $1 / \mathrm{r}$ ratio.) Scans $1-138$ were recorded at $95{ }^{\circ} \mathrm{C}$ and scans $139-158$ at $105^{\circ} \mathrm{C}$. The step at scan 139 is a result of the corresponding temperature increase. The step at scan 19 is due to a $1 \mathrm{~min}$ pause in the data collection. The total time for the 158 scans was $50 \mathrm{~min}$. The ratio increases from 0.2 at $95{ }^{\circ} \mathrm{C}$ to 1.7 at $105{ }^{\circ} \mathrm{C}$.

The result for the high melting sample (Figure 13) suggests that the initially strongest peak in the melt spectra, which is positioned at the right-hand side for the high melting sample (not shown), corresponds to the form present in the solid, which is the $Z$ isomer. We conclude, therefore, that the lefthand peak, which grows in intensity toward a constant ratio $1 / \mathrm{r}$ $=1.7$ after fusion, must correspond to the $E$ isomer. $\mathrm{A}$ 
comparison of Figures 12 and 13 also shows that for the high melting sample (base exposure) the isomerization is much slower than for the low melting sample (exposed to acid). These results are consistent with previous evidence that (i) in solution or in the liquid state, phenylhydrazones and derivatives and other related compounds like oximes and semicarbazones, form mixtures of $E$ and $Z$ isomers; ${ }^{29-33}$ (ii) the formation of an equilibrium $E-Z$ mixture can be catalyzed by traces of acid, ${ }^{29,30,32,37}$ phenylhydrazine, ${ }^{38}$ and, in particular, halogenated solvents; ${ }^{39}$ (iii) slow thermal $E-Z$ isomerization was observed by Tayyari et al. for an acid free sample of acetaldehyde 2,4-dinitrophenylhydrazone $(\mathrm{ADNPH})$ in the melted state, while acidified samples showed a relatively fast isomerization. ${ }^{37}$ As early as 1938, Bryant had formulated such an observation, also for ADNPH. The author concluded that traces of catalyst, possibly sulfuric acid, induce a rapid isomerization and that the lower melting form possibly equals an "equilibrium mixture" of dynamic isomers.

Solution to the Problem of the Different Melting Points. A possible explanation for the peculiar melting behavior of the two different APH samples can now be found on thermodynamic grounds. The thermodynamic equilibrium state for the melt is one with an isomer ratio $E$ / $Z=1.7$, while for the solid state it corresponds to a pure $Z$ compound. As long as the isomerization process in the melt is instantaneous, we expect the melting temperature to be found at the thermodynamic melting temperature $\left(T_{\mathrm{m}, \mathrm{A}}\right.$ in Figure 14). The subscript A labels the low melting (acid) sample that

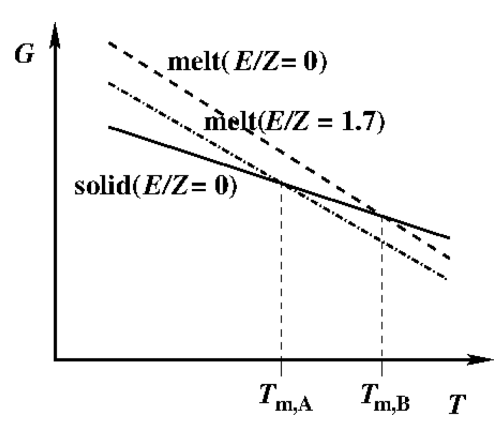

Figure 14. Schematic representation of the temperature dependence of the Gibbs energy for the solid phase, containing only the $Z$-isomer, and for two melt phases, with their isomeric ratio $E / Z$ indicated as a function of temperature. The dashed line represents a metastable molten phase with only the $Z$-isomer present. The acid containing low melting sample A has a lower melting point as compared to the sample B containing some base due to the slow isomerization of the melt toward its equilibrium ratio $E / Z=1.7$.

shows relatively fast isomerization. In the same figure the Gibbs free energy of a metastable melt consisting of only the Zisomer is drawn schematically. For a high melting sample with subscript $\mathrm{B}$ (ase) in the figure the initial melt contains only the $Z$ isomer, and together with the relatively slow isomerization, this will result in a longer lifetime of such a metastable melt. Therefore, the melting temperature will also be found at a higher value $\left(T_{\mathrm{m}, \mathrm{B}}\right.$ in Figure 14$)$ compared to the low melting sample.

This interpretation of the different melting behavior is expected to have also consequences for the crystallization kinetics. In particular a high melting compound is expected to crystallize more easily in case one does not wait too long after the initial melting has occurred because then the $Z$ species is still the majority isomer.

This behavior is clearly visible in NMR experiments of APH recrystallization from the melt. During the crystallization of a low melting sample at $40{ }^{\circ} \mathrm{C}$, the $E / Z$ ratio is essentially kept unaltered (Figure 15), and no residual liquid peaks are

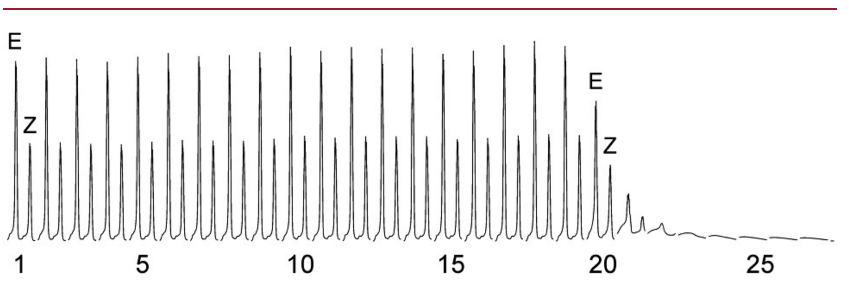

Figure 15. ${ }^{1} \mathrm{H}$ NMR spectrum $(400 \mathrm{MHz})$ measured during crystallization of a low melting $\mathrm{N}$-sample; shown are the repeatedly recorded methyl peaks in 27 scans. A constant $E / Z$ ratio of 1.7 is maintained during cooling of the liquid and also during solidification, where removal of the $Z$ conformer from the liquid phase is compensated by a fast $E$ to $Z$ conversion. The numbers label the consecutive scans; at scan number 19 the solidification commences.

measured after solidification as a result of the fast isomerization for such a sample. Nevertheless, easy crystallization for a low melting sample was observed in only a few experiments. Nucleation indeed is also problematic for crystallization from solution for a low-melting sample. This is likely to be related to the acid concentration, which promotes an isomerization which is too fast for a $Z$-nucleus to reach a critical size.

For high melting samples, however, crystallization proved to be difficult in all NMR experiments, once the equilibrium isomer ratio in the melt was reached. Such a sample had to be cooled down to $0{ }^{\circ} \mathrm{C}$ for the crystallization to occur and it took $22 \mathrm{~h}$ to achieve complete solidification (Figure 16). Figures 17

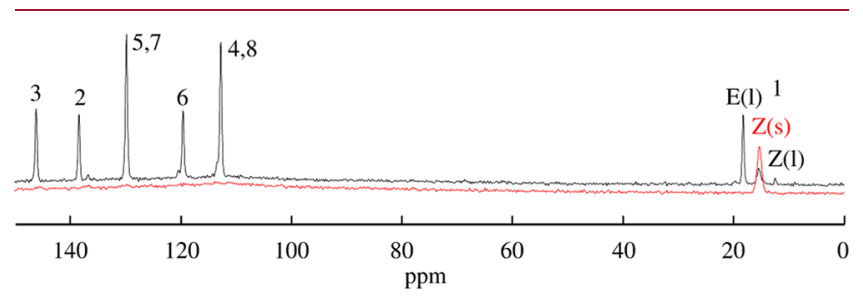

Figure 16. ${ }^{13} \mathrm{C}$ NMR single pulse spectrum of a high melting $\mathrm{N}$ sample (100 MHz, MAS-rate: $5 \mathrm{kHz}, n=256)$ during (upper trace in black) and at the end of the crystallization process (lower trace in red), which took $22 \mathrm{~h}$ to complete at $0{ }^{\circ} \mathrm{C}$.

and 18 show that initially the fraction of $Z$ isomer in the melt almost fully crystallizes and further crystallization is hindered by the very slow $E(1) \rightarrow Z(1)$ transformation.

Confirmation of the Interpretation from Cycled DSC Experiments. The difficulty in isomerization for the highmelting samples should also be observable by DSC. In particular, the recrystallization temperature of a high melting sample is expected to become lower as the waiting time after melting becomes longer and the $E / Z$ ratio approaches the equilibrium value of 1.7. Figure 19 shows the result of a series of heating and cooling DSC runs for a high-melting $\mathrm{N}$-sample. The fresh sample was first heated to $160{ }^{\circ} \mathrm{C}$ and held at that temperature for $15 \mathrm{~min}$ before starting the first cooling run. According to the NMR results, this isothermal step was sufficiently long to ensure the attainment of the equilibrium isomer ratio in the melt. 


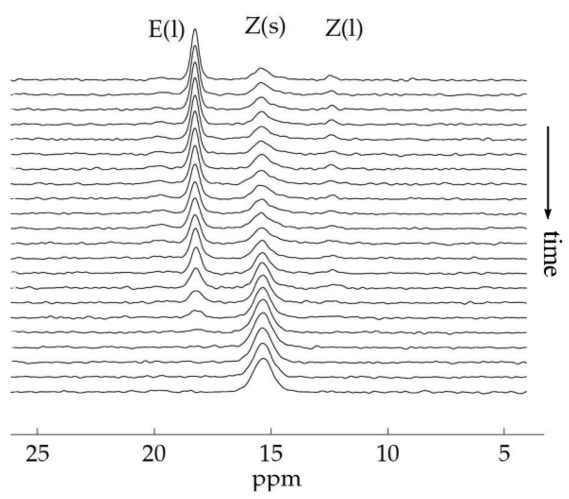

Figure 17. Close-up on the methyl peaks of the NMR spectrum of Figure 16 (at $0{ }^{\circ} \mathrm{C}, \sim 1$ spectrum/h) during crystallization of a high melting $\mathrm{N}$-sample: a growing intensity for the $Z(\mathrm{~s})$-methyl is observed.

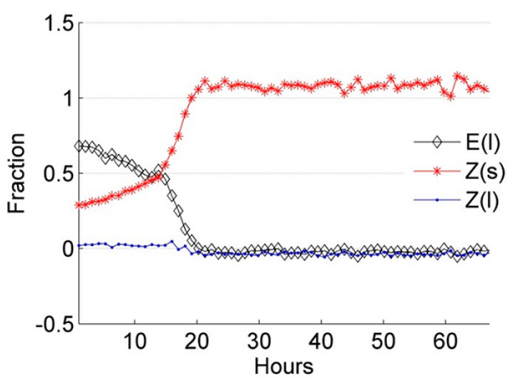

Figure 18. Fractions $E(1), Z(1)$, and $Z(\mathrm{~s})$, determined from the NMR spectra of Figure 17, as a function of time, showing the gradual feed of the $Z$ isomer from the isomerization in the liquid.

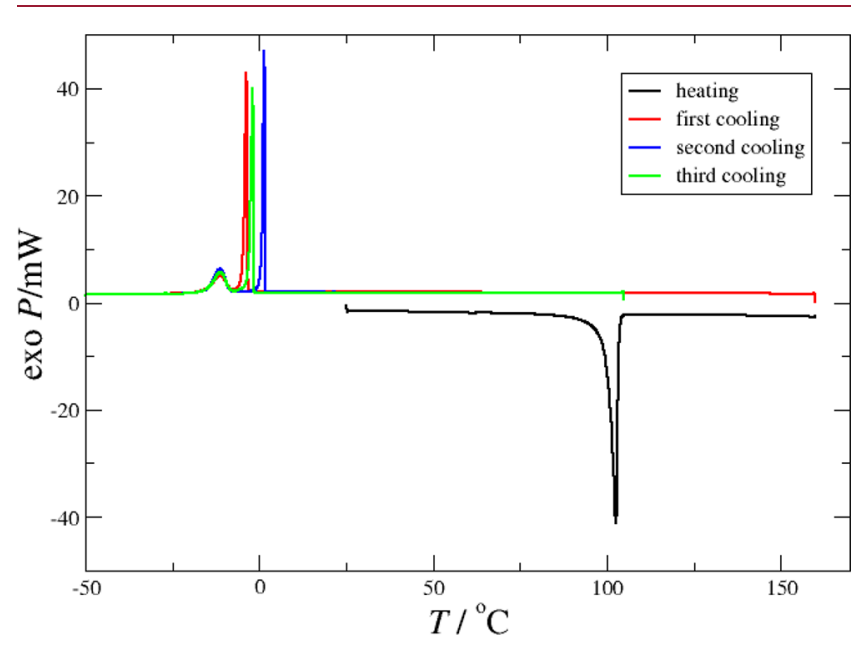

Figure 19. DSC traces of sequential heating and cooling runs of a high melting $\mathrm{N}$-sample. Prior to the first cooling run, the melt is kept at a maximum temperature of $160{ }^{\circ} \mathrm{C}$ for $15 \mathrm{~min}$ to ensure equilibrium isomer ratio formation. All traces were recorded at a rate of $5{ }^{\circ} \mathrm{C} \cdot \mathrm{min}^{-1}$.

No glass transition nor a recrystallization phenomenon was detected on heating, indicating that the crystallized sample was not contaminated with amorphous content which could impact on the enthalpy of fusion measurement. All subsequent heating and cooling runs were carried out between -50 and $105{ }^{\circ} \mathrm{C}$. The observed major exotherms can be assigned to the crystallization of most, but not the complete fraction of the $Z$-isomer in the melt, a situation comparable to time zero in
Figure 18. Assuming that the isomer ratio is more or less constant during these DSC runs in Figure 19, this fraction can now be estimated from the average crystallization enthalpy $\left(\Delta_{\text {cryst }} H_{\mathrm{m}}=-7.3 \mathrm{~kJ} \cdot \mathrm{mol}^{-1}\right)$ and the enthalpy of fusion of the first melting endotherm $\left(\Delta_{\text {fus }} H_{\mathrm{m}}=24.5 \mathrm{~kJ} \cdot \mathrm{mol}^{-1}\right)$. The result is $30 \% \mathrm{Z}$ isomer, which is reasonably close to the equilibrium value of $37 \%(E / Z=1.7)$. As we will see further on, the remaining $7 \%$ recrystallizes gradually on further cooling and finally together with the E-isomer in the small exotherms with an onset of $-9{ }^{\circ} \mathrm{C}$, a temperature which is observed to be constant in the consecutive runs.

The crystallized samples in the consecutive runs of Figure 19 did not have enough time to grow out while depleting the $E$ fraction due to very slow $E(1) \rightarrow Z(1)$ isomerization, at lower temperatures, as was shown in the NMR results (Figures 17 and 18). To further test this time and temperature dependence, we subjected a fresh high melting $\mathrm{N}$-sample to various heating and cooling cycles with different waiting times in the melt (Figure 20).

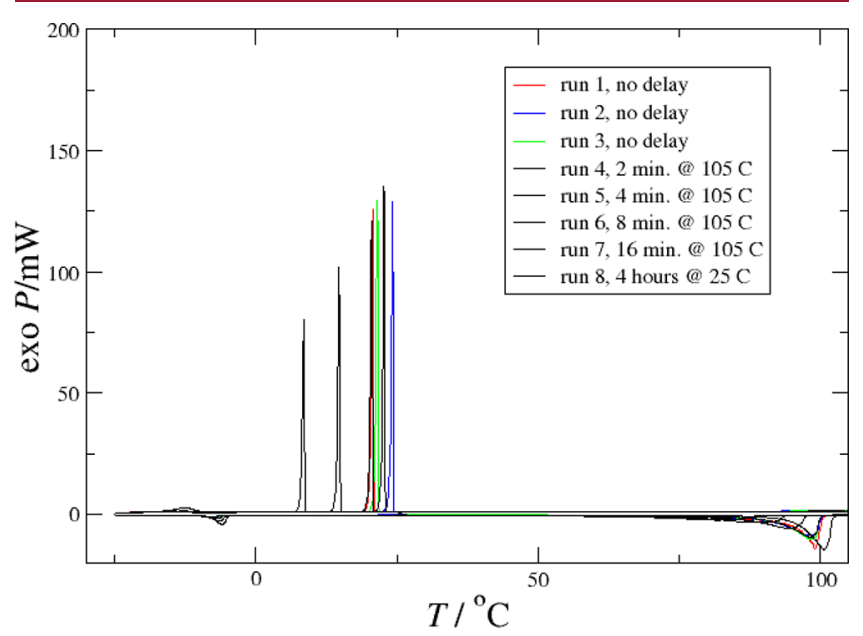

Figure 20. DSC traces of subsequent heating and cooling runs of a high melting N-sample. Each run consists of a heating and cooling trace. For runs $1-3$ no waiting time was applied. After run 3 the sample was held at room temperature for $4 \mathrm{~h}$. For runs 4-7 the sample was held at $105{ }^{\circ} \mathrm{C}$ for the indicated time; heating run 8 was started after waiting for $4 \mathrm{~h}$ at $25^{\circ} \mathrm{C}$. All traces were recorded at a rate of $5^{\circ} \mathrm{C} \cdot \mathrm{min}^{-1}$.

The first three runs in Figure 20 were performed without any postmelting isothermal step, so that a relatively small amount of $E$ isomer is expected to be present at the onset of crystallization. This is consistent with the observation of stronger crystallization exotherms, as compared to Figure 19, and with the fact that the crystallization already starts at $25^{\circ} \mathrm{C}$. Runs 3 and 4 were separated by a waiting time of $4 \mathrm{~h}$ at room temperature, which should lead to a small increase in the amount of $Z$ solid as a result of the $E \rightarrow Z$ conversion. Coherent with this rationale, the crystallization enthalpy of run $4(685.5 \mathrm{~mJ})$ was found to be $6 \%$ higher than that of the previous runs (average value $649.2 \mathrm{~mJ}$ ). In contrast, runs 5-7 show a clear decrease in crystallization enthalpy, due to a larger extent of $Z \rightarrow E$ isomerization in the melt associated with both the increasing waiting time and the higher temperature of 105 ${ }^{\circ} \mathrm{C}$. The final run 8 was started after another $4 \mathrm{~h}$ waiting time at $25{ }^{\circ} \mathrm{C}$ and involved only a heating step. An enlarged plot of Figure 20 for runs $4-8$ solely (Figure 21 ) shows that besides 
the crystallization temperature the fusion onset also decreases with increasing $E$ isomer content in the melt.

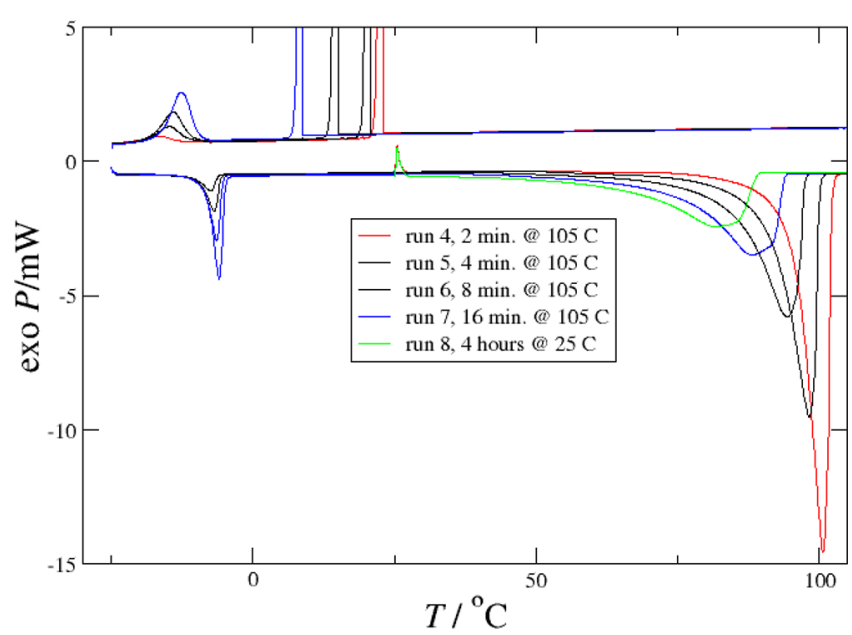

Figure 21. Enlarged plot of the black traces of Figure 20; run 4 is colored in red, run 7 in blue and run 8 in green; runs 4-7 show a gradual decrease of the onset of melting and an increase of the exothermic and endothermic peaks below $0{ }^{\circ} \mathrm{C}$.

The latter observation, a lowering of the melting onset for increasing $E$ isomer in the melt, shows an interesting resemblance with the freezing point depression phenomenon. The considerations and analyses on the purity of the samples as reported in the Supporting Information convinced us that the amount of impurities in the samples was far too small to explain the differences in melting points. If the $E$ isomer is, however, considered as an impurity in the melt of the pure $Z$ isomer solid, it is possible to estimate the corresponding freezing point depression. Assuming the melt to behave as an ideal solution and using $\Delta_{\text {fus }} H(Z)=24.5 \mathrm{~kJ} \cdot \mathrm{mol}^{-1}$ at a fusion temperature of the pure $Z$ solid of $100{ }^{\circ} \mathrm{C}$, as determined from the DSC results, this leads to the freezing point depression curve in Figure 22. In the figure the black line represents the freezing point depression which for the equilibrium isomer ratio value of $E / Z=1.7$ in the melt, corresponding to a mole fraction of $x_{E}=0.63$, would be the maximal freezing point depression. From this point the equilibrium phase lines are drawn in green. All other lines in Figure 22 make it a kinetic eutectic phase diagram for a $Z$ isomer solid and a (possibly partially miscible) $E$ isomer solid for melts with a composition determined by the history of the melt.

The kinetic eutectic phase diagram was constructed based on the results of the DSC experiments in Figure 21. The starting point is a thermodynamic equilibrium between a pure $Z$ solid and a fast isomerizing melt with composition $x_{E}=0.63$ as indicated by the thin green line in the figure. All other fusion temperatures in Figure 22 indicated by the solid black lines should be considered as due to a frozen-in situation of an isomerization reaction obtained at the high temperature hold at $105^{\circ} \mathrm{C}$. An example of this is indicated in Figure 22 with the red line. For every heating run in Figure 21 we assume that the run starts with a pure $Z$ solid and a pure $E$ solid (or a partial solid solution of $E$ and $Z$ isomers). The amount of $E$ becomes larger for every consecutive run in the figure as a result of the waiting time at $105{ }^{\circ} \mathrm{C}$. So the amount of $E$ and $Z$ isomer melting at the eutectic temperature can be determined from the reduction in the corresponding high melting endotherm for

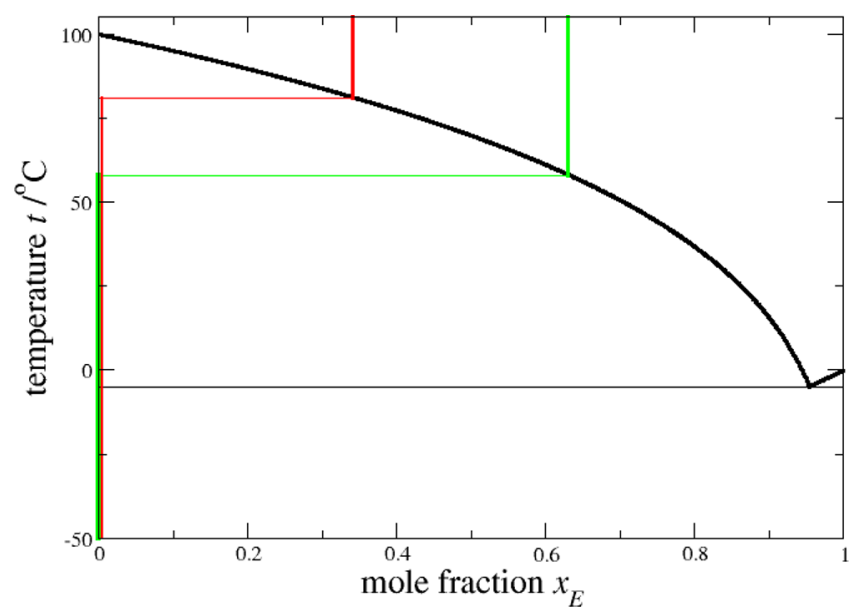

Figure 22. Kinetic eutectic phase diagram (black thick lines) of a pure $Z$ solid as a function of the frozen-in impurity mole fraction of the $E$ isomer, assuming: (i) an ideal solution in the melt; (ii) for the $Z$ isomer, $\Delta_{\text {fus }} H(Z)=24.5 \mathrm{~kJ} \cdot \mathrm{mol}^{-1}$ at $T_{\text {fus }}(Z)=100{ }^{\circ} \mathrm{C}$; and (iii) for the $E$ isomer, a fusion enthalpy $\Delta_{\text {fus }} H(E)=6 \mathrm{~kJ} \cdot \mathrm{mol}^{-1}$ at $T_{\text {fus }}(E)=0$ ${ }^{\circ} \mathrm{C}$. The thick green lines represent the equilibrium phases corresponding to the equilibrium ratio $E / Z=1.7$ in the melt at $x_{E}$ $=0.63$ and a fusion temperature of $58{ }^{\circ} \mathrm{C}$. The red line shows an example of a frozen-in situation for $x_{E}=0.34$. The eutectic is present at $x_{E}=0.95$ and $T=-5{ }^{\circ} \mathrm{C}$.

each consecutive DSC run. This leads for runs 5-8 in Figure 21 , assuming a pure $E$ isomer solid melting at $0{ }^{\circ} \mathrm{C}$, to a melting enthalpy of the $E$ isomer of approximately $6 \mathrm{~kJ} \cdot \mathrm{mol}^{-1}$. This interpretation implies a eutectic temperature of approximately $-5{ }^{\circ} \mathrm{C}$ and also explains the progressive high temperature melting enthalpy curve shapes for increasing $E$ isomer in Figure 21. The increasing enthalpy of the eutectic endotherms at $-10{ }^{\circ} \mathrm{C}$ is then explained by the increasing $E$ isomer concentration, the endotherms being determined by the melting of all the $\mathrm{E}$ isomer molecules together with an amount of $Z$ isomer molecules. Their mutual fraction is equal to the eutectic composition, which is fixed and determined by the kinetic eutectic phase diagram. (A further blow-up of Figure 21 shows indications of very small endotherms at approximately $0{ }^{\circ} \mathrm{C}$, probably due to some $E$ isomer showing delayed melting because of kinetic reasons.) The small deviation of the eutectic temperature $\left(-5{ }^{\circ} \mathrm{C}\right.$ instead of -10 ${ }^{\circ} \mathrm{C}$ ) might be due to the nonideal solution behavior in the melt. Note that in the DSC experiments of Figures 20 and 21 the melt composition in all cases was smaller than the equilibrium value $x_{E}=0.63$, so well below the eutectic composition in Figure 22.

The increasing enthalpy of the eutectic melting peaks shown in Figure 21 for consecutive runs as well as the increasing smearing out of the corresponding high temperature melting endotherms can be very well reconstructed in a DSC modeling study, which is presented in the Supporting Information.

It is important to note that by keeping the high melting $\mathrm{N}$ sample obtained after run 8 overnight in the refrigerator at approximately $5{ }^{\circ} \mathrm{C}$ one can recover the typical melting endotherm in the absence of $E$ isomer, like the black curve in Figure 19. During this time the $E$ melt is depleted through the transformation of $E$ to $Z$ and subsequent growth of the $Z$ solid, as in the case illustrated in of Figures 17 and 18. 


\section{CONCLUSION}

The quality, nature, or structure of the crystals has been the suspect for more than a century in the curious case of acetaldehyde phenylhydrazone, showing unusually large differences in the melting points of materials treated with very small amounts of acid or base. Using modern experimental techniques this cold case was solved, and the perpetrator turns out to be melt and in particular the strong difference in $E / Z$-isomer ratio between the solid and the melt, combined with a slow isomerization in the melt.

This phenomenon adds a fourth category to the relationship between crystalline solids and their melting behavior. Two samples of identical composition of a crystalline solid show:

- Identity if the same crystal structures melt to the same melt

- Isomerism if different crystal structures melt to different melts

- Polymorphism if different crystal structures melt to the same melt

- The curious case discussed here, if the same crystal structures melt to different melts

We do not propose to assign a name to this fourth category first because the situation is likely to be rare and second because the scientific literature is already cluttered with too many unneeded terms. A further category could be considered, where two isomers melt to the same liquid because of an isomerization reaction, aided or not by acid-base catalysis. cisand trans-Azobenzene will qualify as an example, since the conversion of cis to trans in the melt is rapid, even in the

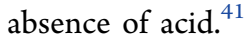

The fourth curious case might be rare, but within the light of the present explanation we can define the conditions for a compound to belong to the curious case category.

First of all the crystal structures must be the same in the temperature range for which the different melting points might be found.

Second, the compound should have a different isomer composition in the equilibrium melt as compared with the crystal structure.

Third, the isomerization reaction rate in the melt should be slow enough to detect the different melts, but tunable by traces of a catalyst.

Candidates can undoubtedly be found for phenylhydrazones other than $\mathrm{APH}$. Interestingly, in contrast to $\mathrm{APH}$, almost all other phenylhydrazones crystallize in a pure $E$ isomer structure, but this will not rule them out as a candidate because the melts may still have a different equilibrium isomer composition.

\section{ASSOCIATED CONTENT}

\section{S Supporting Information}

The Supporting Information is available free of charge on the ACS Publications website at DOI: 10.1021/acs.cgd.8b01459.

Information on the condensation products, single crystal $\mathrm{X}$-ray diffraction of low and high melting point crystals, NMR spectra, computational chemistry data, $E$ and $Z$ isomer assignment in NMR studies and simulations of cyclic DSC experiments of APH (PDF)

\section{Accession Codes}

CCDC 1867806-1867808 (corresponding to TLT671-2b-cc, TLT671-2c-cc. and a condensation product, respectively) contain the supplementary crystallographic data for this paper. These data can be obtained free of charge via www.ccdc.cam.ac.uk/data_request/cif, or by emailing data request@ccdc.cam.ac.uk, or by contacting The Cambridge Crystallographic Data Centre, 12 Union Road, Cambridge CB2 1EZ, UK; fax: +44 1223336033.

\section{AUTHOR INFORMATION}

\section{Corresponding Authors}

*(H.M) E-mail: H.Meekes@science.ru.nl.

*(T.T.) E-mail: T.Threlfall@soton.ac.uk. ORCID

Carlos Bernades: 0000-0003-1490-9728

Simon J. Coles: 0000-0001-8414-9272

Hugo Meekes: 0000-0001-9236-2129

René R. E. Steendam: 0000-0002-3363-4160

Notes

The authors declare no competing financial interest.

\section{ACKNOWLEDGMENTS}

This work was supported in Portugal by Fundação para a Ciência e a Tecnologia (FCT) through Projects LISBOA-010145-FEDER-028401 and UID/MULTI/00612/2013, and a postdoctoral grant awarded to C.B. (SFRH/BPD/101505/ 2014). Southampton authors wish to thank the Engineering and Physical Sciences Research Council for funding the UK National Crystallography Service under its National Research Facilities programme.

\section{REFERENCES}

(1) Fischer, E. Ueber die Hydrazinverbindungen; Erste Abhandlung. Liebig's Ann. Chem. 1878, 190, 67-183; Notizen ueber die Hydrazine. Liebig's Ann. Chem. 1886, 236, 198-199.

(2) Fischer, E. Ueber das Azophenyläthyl und das Acetaldehydphenylhydrazon. Ber. Dtsch. Chem. Ges. 1896, 29, 793-797; Ueber die Phenylhydrazone der Aldehyde. Ber. Dtsch. Chem. Ges. 1897, 30, $1240-1243$

(3) Causse, M. H. Sur les aldéhydates de phénylhydrazine. Compt. Rend. 1896, 122, 1274-1277. Sur l'action de l'aldéhyde éthylique sur la phénylhydrazine et sur deux triéthylidènes-diphénylhydrazones isomériques $\alpha$ et $\beta$, Bull. Soc. Chim. Fr. 1897, 17, 234-249.

(4) Bamberger, E.; Pemsel, W. Zur Kenntniss des Acetaldehydphenylhydrazons. Ber. Dtsch. Chem. Ges. 1903, 36, 85-89.

(5) Lockemann, G.; Liesche, O. Zur Kenntniss des Aethylidenphenylhydrazins. Justus Liebigs Ann. Chem. 1905, 342, 14-50.

(6) Robertson, W. Solubility as a measure of the change undergone by isodynamic hydrazones: (1) camphorquinonephenylhydrazone, (2) acetaldehydephenylhydrazone. J. Chem. Soc., Trans. 1905, 87, $1298-1302$

(7) Laws, E. G.; Sidgwick, N. V. Isomeric acetaldehydephenylhydrazones. J. Chem. Soc., Trans. 1911, 99, 2085-2093.

(8) Threlfall, T. L. Analysis of organic polymorphs. A review. Analyst 1995, 120, 2435-2460.

(9) See, for example Garcia, M. A.; Lopez, C.; Claramunt, R. M.; Kenz, A.; Pierrot, M.; Elguero, J. Polymorphism vs. Desmotropy: The Cases of 3 Phenyl and 5 Phenyl $1 \mathrm{H}$ pyrazoles and 3 Phenyl $1 \mathrm{H}$ indazole. Helv. Chim. Acta 2002, 85, 2763. Bhatt, P. M.; Desiraju, G. R. Tautomeric polymorphism in omeprazole. Chem. Commun. 2007, 0, 2057-2059. Gelbrich, T.; Threlfall, T. L.; Bingham, A. L.; Hursthouse, M. B. Polymorph VI of sulfapyridine: interpenetrating two- and three-dimensional hydrogen-bonded nets formed from two tautomeric forms. Acta Crystallogr., Sect. C: Cryst. Struct. Commun. 2007, 63, o323-o326.

(10) Hooft, R., Nonius, B. V. Collect: Data Collection Software; R. Hooft, B. V. Nonius, 1998. 
(11) Sheldrick, G. M. SADABS, Version 2.10; Bruker AXS Inc.: Madison, Wisconsin, USA, 2003.

(12) Sheldrick, G. M. A short history of SHELXL. Acta Crystallogr., Sect. A: Found. Crystallogr. 2008, 64, 112-122.

(13) Sheldrick, G. M. Crystal structure refinement with SHELXL. Acta Crystallogr., Sect. C: Struct. Chem. 2015, 71, 3-8.

(14) Bernardes, C. E. S.; Piedade, M. F. M.; Minas da Piedade, M. E. Polymorphism in 4'-hydroxyacetophenone: Structure and Energetics. Cryst. Growth Des. 2008, 8, 2419-2430.

(15) Frisch, M. J.; Trucks, G. W.; Schlegel, H. B.; Scuseria, G. E.; Robb, M. A.; Cheeseman, J. R.; Scalmani, G.; et al. Gaussian, Inc.: Wallingford, CT, USA, 2009.

(16) Frisch, M. J.; Head-Gordon, M.; Pople, J. A. A Direct MP2 Gradient Method. Chem. Phys. Lett. 1990, 166, 275-280.

(17) Frisch, M. J.; Head-Gordon, M.; Pople, J. A. Semi-Direct Algorithms for the MP2 Energy and Gradient. Chem. Phys. Lett. 1990, 166, 281-289.

(18) Head-Gordon, M.; Head-Gordon, T. Analytic MP2 Frequencies without Fifth-Order Storage. Theory and Application to Bifurcated Hydrogen-Bonds in the Water Hexamer. Chem. Phys. Lett. 1994, 220, 122-128.

(19) Head-Gordon, M.; Pople, J. A.; Frisch, M. J. MP2 Energy Evaluation by Direct Methods. Chem. Phys. Lett. 1988, 153, 503-506.

(20) Grimme, S.; Antony, J.; Ehrlich, S.; Krieg, H. A consistent and accurate $\mathrm{ab}$ initio parametrization of density functional dispersion correction (DFT-D) for the 94 elements H-Pu. J. Chem. Phys. 2010, 132, 154104-154119.

(21) Koch, W.; Holthausen, M. C. A. Chemist's Guide to Density Functional Theory, 2nd ed.; Wiley-VCH: Weinheim, 2002.

(22) Becke, A. D. Density-Functional Thermochemistry. III. The Role of Exact Exchange. J. Chem. Phys. 1993, 98, 5648-5652.

(23) Stephens, P. J.; Devlin, F. J.; Chabalowski, C. F.; Frisch, M. J. $\mathrm{Ab}$-Initio calculation of vibrational absorption and circular-dichroism spectra using density-functional force-fields. J. Phys. Chem. 1994, 98, $11623-11627$.

(24) Kendall, R. A.; Dunning, T. H.; Harrison, R. J. ElectronAffinities of the 1st-Row Atoms Revisited - Systematic Basis-Sets and Wave-Functions. J. Chem. Phys. 1992, 96, 6796-6806.

(25) Wilson, A. K.; Woon, D. E.; Peterson, K. A.; Dunning, T. H. Gaussian Basis Sets for Use in Correlated Molecular Calculations. IX. The Atoms Gallium Through Krypton. J. Chem. Phys. 1999, 110, $7667-7676$

(26) Woon, D. E.; Dunning, T. H. Gaussian-Basis Sets for Use in Correlated Molecular Calculations. III. The Atoms Aluminum through Argon. J. Chem. Phys. 1993, 98, 1358-1371.

(27) Woon, D. E.; Dunning, T. H. Gaussian-Basis Sets for Use in Correlated Molecular Calculations. IV. Calculation of Static Electrical Response Properties. J. Chem. Phys. 1994, 100, 2975-2988.

(28) Range, S.; Bernardes, C. E. S.; Simões, R. G.; Epple, M.; Minas da Piedade, M. E. Size Matters: An Experimental and Computational Study of the influence of particle size on the Lattice Energy of $\mathrm{NaCl}$. J. Phys. Chem. C 2015, 119, 4387-4396.

(29) Karabatsos, G. J.; Graham, J. D.; Vane, F. M. Syn-anti isomer determination of 2,4-dinitrophenylhydrazones and semicarbazones by n.m.r. J. Am. Chem. Soc. 1962, 84, 753-755.

(30) Karabatsos, G. J.; Shapiro, B. L.; Vane, F. M.; Fleming, J. S.; Ratka, J. S. Structural studies by nuclear magnetic resonance II. Aldehyde 2,4-dinitrophenylhydrazones. J. Am. Chem. Soc. 1963, 85, 2784-2788.

(31) Karabatsos, G. J.; Taller, R. A. Structural studies by nuclear magnetic resonance. V. Phenylhydrazones. J. Am. Chem. Soc. 1963, 85, 3624-3629.

(32) Karabatsos, G. J.; Vane, F. M.; Taller, R. A.; Hsi, N. Structural studies by nuclear magnetic resonance VIII. Ring-substituted phenylhydrazones, semicarbazones, and thiosemicarbazones. J. Am. Chem. Soc. 1964, 86, 3351-3357.

(33) Karabatsos, G. J.; Taller, R. A. Structural studies by nuclear magnetic resonance XIX. N,N-dimethylhydrazones and general comments on configurational and conformational isomerism. Tetrahedron 1968, 24, 3923-3937.

(34) Herbstein, F. H. Acta Crystallogr., Sect. B: Struct. Sci. 2000, 56, 547-557.

(35) Gordon, M. S.; Sojka, S. A.; Krause, J. G. Carbon-13 NMR of para-substituted hydrazones, phenylhydrazones, oximes, and oxime methyl ethers: substituent effects on the iminyl carbon. J. Org. Chem. 1984, 49, 97-100.

(36) Barchiesi, E.; Bradamante, S.; Carfagna, C.; Ferraccioli, R. Transmission of substituent effects through the methyleneamino group $\mathrm{N}=\mathrm{CH}$ : aldehyde phenylhydrazones and conjugate anions. $J$. Chem. Soc., Perkin Trans. 2 1988, 8, 1565-1572.

(37) Tayyari, S. F.; Speakman, J. L.; Arnold, M. B.; Cai, W.; Behforouz, M. A comprehensive investigation of variations in melting ranges and NMR data of 2,4-dinitrophenylhydrazine derivatives. J. Chem. Soc., Perkin Trans. 2 1998, 10, 2195-2200.

(38) Bellamy, A. J.; Hunter, J. EZ-isomerism in alkyl phenyl ketone phenylhydrazones and acetaldehyde phenylhydrazone. J. Chem. Soc., Perkin Trans. 1 1976, 4, 456-458.

(39) Stassinopoulou, C. I.; Zioudrou, C.; Karabatsos, G. J. Solvent effects on the syn-anti isomerization rates of hydrazones of acetone. Tetrahedron 1976, 32, 1147-1151.

(40) Bryant, W. M. D. Dynamic Isomerism of Acetaldehyde 2,4Dinitrophenylhydrazone. J. Am. Chem. Soc. 1938, 60, 2814-2815.

(41) Wolf, E.; Cammenga, H. K. Thermodynamic and Kinetic Investigation of the Thermal Isomerization of Cis-azobenzene. $Z$. Phys. Chem. 1977, 107, 21-38. 